\title{
Osteosíntese de fratura metafisária femural de cães com pinos de Steinmann introduzidos pela crista troclear
}

\section{Osteosynthesis of femoral metaphyseal fracture in dogs with Steinmann pins inserted through troclear ridges}

\author{
Alceu Gaspar Raiser," landara Silva Silveira," Gláucia Kommers“*”
}

\begin{abstract}
Resumo
Dezoito cães sem raça definida, com idade entre 2 e 12 anos e peso entre 5 e $8 \mathrm{~kg}$ sofreram fratura iatrogênica da metáfise femoral em um dos membros. Feita redução, cada fratura foi imobilizada pela introdução normógrada de um pino de Steinmann através da crista da tróclea, penetrando até a metáfise proximal. As avaliações clínica, radiográfica e histológica demonstraram que até 90 dias após redução, as fraturas transversais estavam consolidadas e em franco processo de remodelação.
\end{abstract}

Palavras-chave: cirurgia; traumatismo; fêmur.

\section{Introdução}

As fraturas distais do fêmur são mais comuns em animais adultos (Milton, 1993) e podem ser classificadas em metafisárias, fisárias e epifisárias. As metafisárias, embora não sejam comuns, representam um desafio ao cirurgião ortopédico para repará-las, porém, seu rico suprimento sangüíneo permite rápida cicatrização (Gilmore, 1990). As formas transversal e moderadamente cominutiva têm maior prevalência nessa área entre a diáfise e a epífise. $O$ pequeno segmento distal à fratura e a presença de um canal medular amplo dificultam a imobilização particularmente com pinos intramedulares (Milton, 1993). A estabilização das fraturas metafisárias pode ser efetuada com placa em cães grandes. Os pinos intramedulares são mais apropriados para animais de pequeno e médio porte. Estão indicados também pinos cruzados ou pinos intramedulares duplos introduzidos a partir dos côndilos, podendo ser utilizados pinos de Rush ou de Steinmann (Gilmore, 1990).

Segundo Roush (1995), a reparação de fraturas requer redução anatômica, rígida estabilidade e recuperação precoce da função do membro. Uma rígida estabilização elimina a mobilidade na linha de fratura assegurando conforto para o animal ao utilizar o membro, resultando em manutenção do tono e da massa muscular, mobilidade e nutrição articular. Assegura, ainda, apoio do membro e manutenção da densidade óssea.
Belkoff et al. (1992) citaram que tanto a imobilização óssea muito rígida como a frágil podem retardar a união óssea. O uso de apenas um pino na imoblização de fraturas resiste às forças de rotação se for adequadamente adaptado e houver estabilidade nas bordas dos segmentos fraturados.

Quando houver instabilidade óssea por imobilização inadequada ou sustentação de peso excessivo, pode formarse um calo instável que, mesmo assim, pode permitir a cicatrização. Se a instabilidade for superior à capacidade do calo em estabilizar a fratura, poderá ocorrer união retardada ou não-união. Tanto no primeiro como no segundo caso, além da imobilização inadequada dos segmentos fraturados, freqüentemente está associado pobre suprimento sangüíneo (Hoefle, 1993).

Segundo Woodard \& Riser (1991), a não-união deve-se à deficiência primária em que são oferecidas condições para cicatrização, mas o mecanismo biológico falha ou é secundária à inadequada imobilização que é a forma mais comum em medicina humana e veterinária. Havendo mobilidade controlada na linha de fratura, o calo ósseo pode ser precedido pela formação de um calo cartilaginoso; porém, com mobilidade excessiva, ocorrerá não-união ou união retardada com formação de tecido fibroso.

Para Hulse \& Aron (1994) a imobilização articular cria considerável perda de proteoglicanos articulares e substancial lesão estrutural na superfície e camadas superficiais da

\footnotetext{
* Professor Titular, Curso de Pós-graduação em Medicina Veterinária, área de Cirurgia, Universidade Federal de Santa Maria (UFSM). Endereço para correspondência: Rua Dr. Pantaleão, 587, apto. 303, 97010-180, Santa Maria, RS. e-mail: raisermv@ smnet.com.br

** Professora Adjunto I, Departamento de Medicina Veterinária, UNIDERP, Campo Grande, MS.

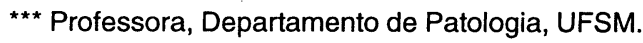


cartilagem articular. Já a atividade física diminui o tempo para recuperação e evita as complicações associadas à contratura dos tecidos moles adjacentes à área operada. Portanto, o tipo e intensidade da atividade dependerá da estabilidade oferecida pelo método de imobilização (Gentry \& Mann, 1993).

A fenilbutazona e o ácido acetilsalicílico proporcionam analgesia de grau moderado, não sendo adequados para o período pós-operatório imediato de pacientes ortopédicos (Gentry \& Mann, 1993).

O paciente ortopédico deve receber nutrição adequada à demanda durante a recuperação otimizando a cicatrização (Gentry \& Mann, 1993). Silveira et al. (1997) verificaram em estudo experimental que fraturas distais do fêmur apresentavam evolução cicatricial mais rápida quando os cães foram alimentados com ração contendo teor de proteína bruta equivalente a $27 \%$, comparado ao teor de $21 \%$.

A presente pesquisa buscou avaliar a imobilização de fraturas metafisárias de fêmur pela introdução normógrada de dois pinos de Steinmann a partir das cristas da tróclea como alternativa para reparação.

\section{Material e métodos}

Dezoito cães sem raça definida, clinicamente sadios, com peso variando entre 5 e $8 \mathrm{~kg}$, idade entre 2 e 12 anos, oriundos do Biotério Central da Universidade Federal de Santa Maria, foram submetidos a fratura iatrogênica da metáfise distal do fêmur e submetidos a osteosíntese, sendo observados por 60 (grupo I - 9 animais) e 90 dias (grupo II) quanto à evolução cicatricial.

No pré-operatório cada animal foi medicado com maleato de acepromazina $(0,2 \mathrm{mg} / \mathrm{kg})$ e citrato de fentanila $(0,005 \mathrm{mg} /$ $\mathrm{kg}$ ) aplicados em "bolus" por via intramuscular e ampicilina sódica $(20 \mathrm{mg} / \mathrm{kg})$, via intravenosa, 30 minutos antes da intervenção. Após foram higienizados e submetidos à tricotomia do membro posterior esquerdo. No bloco cirúrgico, cada paciente teve indução anestésica com Tiopental sódico $(10 \mathrm{mg} / \mathrm{kg})$ e foram mantidos em plano anestésico com halotano em sistema de ventilação com duplo $T$ de Baraka.

Após contenção em mesa cirúrgica, cada cão foi submetido a anti-sepsia e delimitação da área operatória com panos de campo. Na seqüência foi efetuada abordagem dorso-lateral iniciando no $1 / 3$ distal do fêmur e estendendo-se até o 1/3 distal da tíbia. Assim, após artrotomia e luxação da patela foi obtida exposição da porção distal do fêmur, articulação do joelho e porção proximal da tíbia. A seguir foi induzida fratura iatrogênica em nível da metáfise do fêmur.

A fratura foi reduzida com duas pinças ósseas de encaixe fixo e estabilizada com dois pinos de Steinmann, cada um adaptado a partir da crista medial e lateral da tróclea respectivamente (Figura 1A), introduzidos paralelamente em sentido proximal, com auxílio de condutor manual de Jacob.
Os pinos foram conduzidos até ser obtida inserção firme no segmento proximal do fêmur. O excedente foi seccionado junto à tróclea e sepultado na região subcondral (Figura 1B) com o uso de recalcador ortopédico. A seguir a região operatória foi irrigada abundantemente com solução salina isotônica, morna, efetuada redução da luxação patelar e capsulorrafia com fio de poliamida 0,20 (náilon de pesca). Os demais planos abordados foram reduzidos com o mesmo fio. O diâmetro dos pinos utilizados para imobilização da fratura variou de 1,5 a 1,8mm, na dependência do peso dos animais.

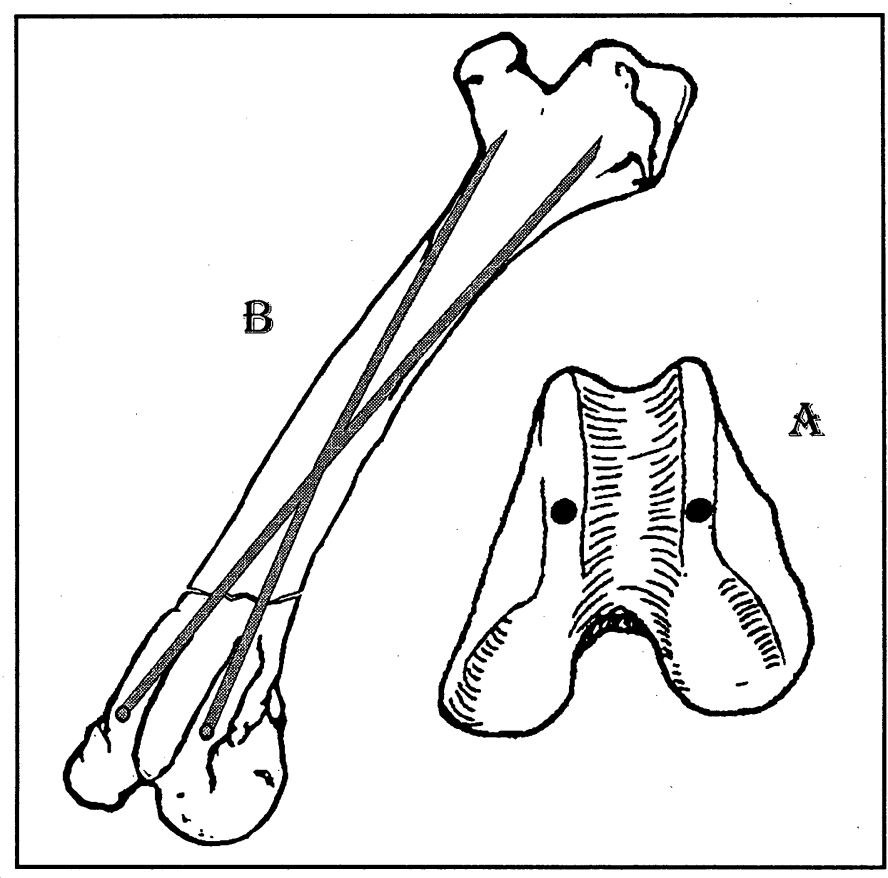

Figura 1: Esquema representativo dos pontos de inserção dos pinos de Steinmann (A) e disposição após a introdução e sepultamento (B), na estabilização de fraturas metafisárias distais do fêmur.

Ao término da cirurgia foi adaptada bandagem leve e administrado flunixim meglumine $(1 \mathrm{mg} / \mathrm{kg})$ repetido a cada 24 horas por três dias. Foi efetuado, ainda, controle radiográfico logo após a cirurgia e aos 60 e/ou 90 dias de evolução cicatricial.

Todos os cães tiveram liberdade de movimento a partir do pós-operatório imediato, sendo mantidos em canis individuais até a retirada dos pontos cutâneos (7 dias). Após foram acomodados em canis coletivos, em grupos de cinco, sendo exercitados diariamente, no início em passeios com guia e depois soltos. Cada animal recebeu $200 \mathrm{~g} / \mathrm{dia}$ de ração comercial para cães com teor de proteína bruta de $27 \%$.

Ao término do período de observação previsto, os cães foram sacrificados e encaminhados para necropsia. Foi colhido segmento do fêmur correspondente à área de fratura e epífise distal que foi fixado em formol neutro a $10 \%$, 
depois descalcificado em solução aquosa de ácido fórmico a $10 \%$, tamponada com citrato de sódio para $\mathrm{pH} 4,5$ por três dias e, após, lavado em água corrente por 24 horas e clivado. Fragmentos da área cicatricial foram incluídos em parafina, cortados a $5 \mathrm{~m}$ e corados pela hematoxilina eosina.

\section{Resultados e discussão}

A presença de edema no pós-operatório foi discreta e os cães mantinham-se em estação apoiando o membro a partir da recuperação anestésica, ainda no primeiro dia. A partir do terceiro dia houve melhora progressiva e do quinto ao sétimo dia não se observou limitação do movimento durante as caminhadas (ausência de claudicação). O uso de analgésico e antiinflamatório como o flunixin meglumine, associado a adequada estabilização da fratura é um dos fatores que contribuíram para que os animais recuperassem o apoio do membro precocemente. Embora Gentry \& Mann (1993) tenham afirmado que a fenilbutazona e o ácido acetilsalicílico não sejam adequados para analgesia em ortopedia, no presente experimento observou-se que o flunixin meglumine alcançou tal objetivo e associado à estabilização adequada da fratura minimizaram a dor durante a deambulação.

A colocação dos dois pinos por via normógrada através das bordas da tróclea, com auxílio de perfurador de Jacob, estando a fratura reduzida e estabilizada por pinças ósseas de encaixe fixo, proporcionou estabilidade à linha de fratura tão logo os pinos foram introduzidos até a porção proximal do fêmur e o sepultamento de ambos e a redução da luxação patelar permitiu ampla mobilidade da articulação do joelho.

A técnica de imobilização com dois pinos de Steinmann introduzidos a partir da tróclea é uma variação das técnicas citadas por Gilmore (1990) e que tem as mesmas vantagens de estabilização prevenindo a flexão e a rotação, o que nem sempre é possível com a utilização de um pino, como citaram Belkoff et al. (1992). Considerando que o fêmur tem canal medular curvo, é fundamental que sejam utilizados pinos flexíveis e que sejam introduzidos com auxílio de condutor e não perfurador manual para que possam deslizar pela face endosteal da cortical e alcançar a porção proximal do fêmur.

Embora o método de abordagem utilizado no atual experimento tenha invadido a articulação do joelho, foram importantes os cuidados com a assepsia, uso profilático de antibiótico, a irrigação abundante com solução salina morna e adequada capsulorrafia. Como os pinos foram sepultados sob a cartilagem (Figura 2), a técnica proposta evitou uma segunda intervenção para remoção dos implantes. Essa técnica dispensa a flexão dos pinos que se faz necessária no método citado por Gilmore (1990) que usa pontos lateral e medial à tróclea e nenhum dos cães do atual experimento apresentou evidência de lesão articular.

Os exames radiográficos feitos no pós-operatório imediato demonstraram mau alinhamento do fêmur em três cães com fratura oblíqua, verificando-se deslocamento caudal da ex-

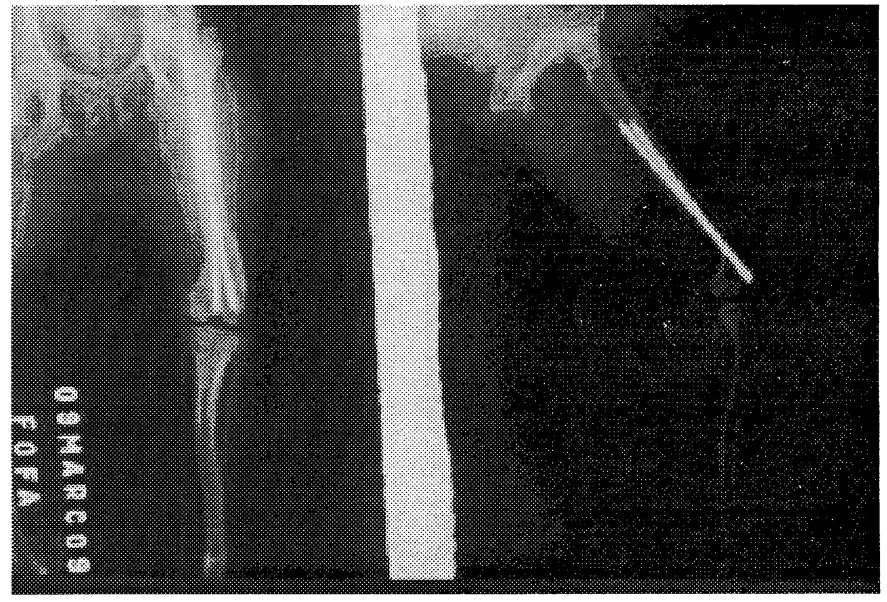

Figura 2: Aspecto radiográfico da evolução cicatricial da metáfise femural de um cão aos 90 dias após imobilização de fratura transversal. Observar posição dos pinos no canal medular.

tremidade distal do segmento proximal. Embora esses animais tenham manifestado sinais de claudicação, somente no segundo mês de evolução pós-operatória, ainda não apresentavam consolidação óssea e detectou-se migração de um ou dos dois pinos para a articulação. Aos 90 dias de evolução um cão ainda apresentava consolidação incompleta na linha de fratura. Nos demais o processo havia se consolidado aos 60 dias de evolução e já havia imagem de remodelação com evidenciação da cortical reconstituída aos 90 dias de pós-operatório. Essa migração dos pinos decorreu da falta de estabilidade na linha de fratura, onde a contração muscular causou deslocamento proximal do segmento ósseo distal projetando os pinos pelos orifícios de penetração na tróclea. Portanto, esta técnica não é apropriada para fraturas metafisárias oblíquas.

Pela avaliação histológica aos 60 dias observou-se presença de tecido ósseo esponjoso e cortical contínua além de tecido fibrocartilaginoso em um cão e cartilaginoso em outros dois. Aos 90 dias um cão não apresentava evidência de cicatrização (Figura 3), dois evidenciavam cortical

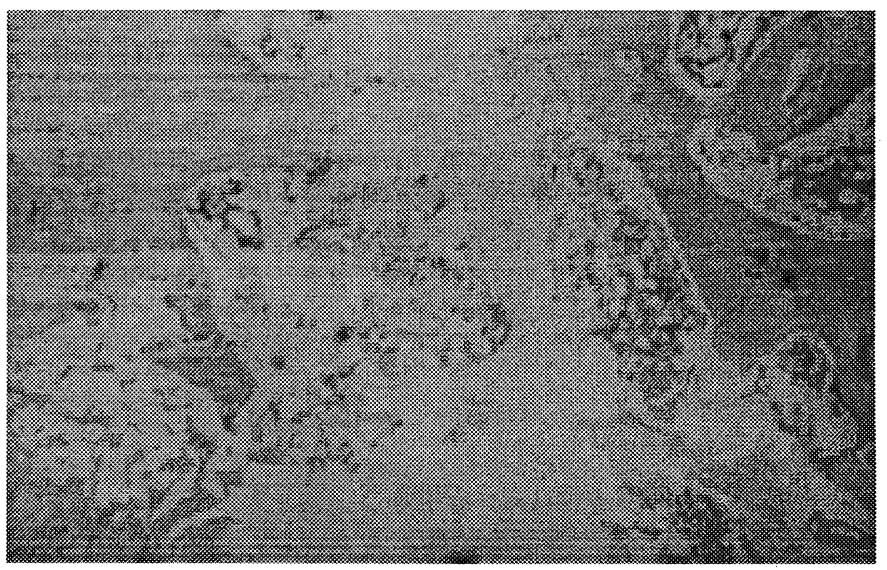

Figura 3: Aspecto histológico da não-união óssea de um cão aos 90 dias de imobilização em fratura oblíqua da metáfise femural. 
unido por tecido esponjoso e proliferação conjuntiva no endósteo. Nos demais já se observava intensa atividade osteoclástica, indicando processo de remodelação.

O retardamento ou ausência de cicatrização nos três cães deveu-se à redução e imobilização inadequadas, prejudicando a mobilidade do membro que, segundo Woodard \& Riser (1991) e Hoefle (1993), é a principal causa de não união em medicina veterinária. Segundo essès autores, a não-união fibrosa é conseqüência de mobilidade. Isso explica o achado histológico do cão com não-união (Figura 3), que evidenciava apenas proliferação fibrocartilaginosa. Já no fêmur dos outros dois a presença de tecido cartilaginoso mostra instabilidade que retardou, mas não impediu a formação de tecido ósseo, a qual foi comprovada radiograficamente aos 90 dias de evolução.

Uma rápida recuperação da mobilidade no membro tem como vantagem a prevenção da atrofia muscular, o que foi constatado na maioria dos cães. A inadequada redução da fratura evidenciada nos três cães com fratura oblíqua foi associada a início de claudicação de exercício ao redor dos 38, 45 e 50 dias após a cirurgia. Sem dúvida, deveu-se à migração dos pinos que se constatou radiograficamente aos 60 dias e prejudicou a deambulação. A restrição de exercício é uma das causas de não-união ou união retardada que, segundo Gentry \& Mann (1993) e Hulse \& Aron (1994), interfere com a funcionalidade de tecidos moles e articulações adjacentes.

O estudo radiográfico demonstrou que a utilização de dois pinos flexíveis permitiu adequada imobilização das fraturas transversais, distais de fêmur. Naquelas oblíquas reco- menda-se avaliar a associação de cerclagem para obter suficiente imobilização. É interessante assinalar que a estabilidade obtida por essa metodologia deve-se aos efeitos antiflexão e anti-rotação dos implantes. No entanto, cabe ressaltar que as fraturas estáveis, ou seja, de bordas irregulares, oferecem melhor evolução, pois a intensa contração da massa muscular da coxa permite redução com significativo grau de compressão na linha de fratura, obtendo-se mais rápida cicatrização.

Não foi observada variação no processo de cicatrização dos animais deste experimento, em relação à idade. Todos eram adultos, mas evidenciavam faixas etárias distintas. Assim, animais mais velhos (12 anos) apresentaram cicatrização semelhante aos mais novos (4 anos). Esse dado demonstra que a influência da idade não é significativa entre cães adultos, desde que tenham acesso a um suprimento alimentar adequado. Assim, a administração de dieta com alto teor protéico influenciou positivamente na cicatrização como já haviam citado Gentry \& Mann (1993) e Silveira et al. (1997). No entanto, se a imobilização não for adequada, o processo retarda ou não se estabelece.

\section{Conclusão}

Em face dos resultados obtidos, pode-se inferir que a introdução normógrada de dois pinos de Steinmann pelas cristas da tróclea permite estabilização de fraturas metafisárias transversais, com rápido retorno da deambulação, dispensando a remoção dos implantes após a cicatrização óssea. Fraturas oblíquas não são adequadamente estabilizadas por essa técnica.

\section{Abstract}

Eighteen mongrel dogs, with age among two and twelve years old, weighing 5 to $8 \mathrm{~kg}$ were submitted to iatrogenic fracture of the femoral metaphysis. Fractures were repaired with two Steinmann pins inserted through the lateral and medial trochlear ridges and driven across de fracture line until they engage the proximal metaphysis of the femur. Fractures healing were evaluated with clinical, radiological and histopathological studies.

At the ninety post-operative day transverse fracture of the metaphisis were consolided and in remodelating phasis.

Keywords: surgery; trauma; femur.

\section{Referências bibliográficas}

BELKOFF, S. M., MILLIS, D. L., PROBST, C. W. Biochemical comparison of three internal fixations for treatment of splited capital femoral epiphisis in immature dogs. Amer $J$ Vet Res, v. 53, n.11, p. 2136-2140, 1992.

GENTRY, S. J., MANN, F. A. Postoperative care of canine and feline orthopedic patients. J Amer Anim Hosp Assoc, v. 29, n. 2, p. 146-150, 1993.

GILMORE, D. R. Internal fixation of femoral fractures. p. 682 694. In: Bojrab M J, Current techniques in small animal surgery. 3rd. ed., Lea \& Febiger, Philadelphia, 1990.

HOEFLE, W. D. Delayed fracture union, nonunion, and malunion, p. 689-691. In: Bojrab M J. Disease mechanisms in small animal surgery. 3rd ed. Cap. 100, Lea \& Febiger, Philadelphia, 1993.
HULSE, D. A., ARON, D. N. Advances in small animal orthopedics. Comp Cont Educ Pract Vet, v. 16, n. 7, p. 831832, 1994.

MILTON, J. L. Fractures of the femur, p. 1805-1817. In: SLATTER, D.H. Textbook of small animal surgery. v. 2, 2nd. ed., Saunders, Philadelphia, 1993.

ROUSH, K. J. 1995. Fracture management decisions. Vet Clin North Amer: Small Anim Pract, v. 25, n. 5, p.1059-1072.

SILVEIRA, I. S., RAISER, A. G., POLYDORO, A. S., DOS SANTOS, M. N. Efeitos da dieta na cicatrização de fraturas distais de fêmur imobilizadas com pinos intramedulares em cães. Acta Cir Bras, v. 12, n. 3, p. 178-181, 1997.

WOODARD, J. C., RISER, W. H. Morphology of fracture nonunion and osteomyelitis. Vet Clin North Amer: Small Anim Pract, v. 21 , n. 4 , p. 813-844, 1991. 